\title{
A EXPERIÊNCIA DEMOCRÁTICA DE ANÍSIO TEIXEIRA: O PROJETO DO CENTRO EDUCACIONAL CARNEIRO RIBEIRO
}

\author{
LA EXPERIENCIA DEMOCRÁTICA DE ANÍSIO TEIXEIRA: EL PROYECTO DEL \\ CENTRO EDUCACIONAL CARNEIRO RIBEIRO
}

\author{
ANÍSIO TEIXEIRA'S DEMOCRATIC EXPERIENCE: CARNEIRO RIBEIRO \\ EDUCATIONAL CENTER
}

\author{
Lucas Silva TEIXEIRA ${ }^{1}$
}

\begin{abstract}
RESUMO: Anísio Teixeira faz parte do grupo de educadores brasileiros que se propuseram a pensar a educação no Brasil e a praticá-la em sua vida pública. Em contato com a filosofia pedagógica de John Dewey, Anísio baseou seu pensamento e expandiu-o, adaptando-o para a realidade e necessidades da sociedade brasileira. O presente artigo tem a finalidade de analisar a criação de um dos seus projetos, o Centro Educacional Carneiro Ribeiro, sob a ótica da democracia presente no pensamento deweyano e anisiano. Para isso, se faz uma breve passagem pela pedagogia de Dewey, adentrando em sua concepção de democracia e como ela influencia sua visão pedagógica e, a partir daí, se compara com os objetivos pretendidos por Anísio com a criação do Centro em bairro operário, de Salvador, no fim da década de 40.
\end{abstract}

PALAVRAS-ChAVE: Anísio Teixeira. Democracia. Educação democrática. Centro Educacional Carneiro Ribeiro.

RESUMEN: Anísio Teixeira hace parte del grupo de educadores brasileños que se propusieron a pensar la educación en Brasil y a practicarla en su vida pública. En contacto con la filosofía pedagógica de Jonh Dewey, Anísio Teixeira basó su pensamiento y lo expandió adaptándolo a la realidad y necesidades de la sociedad brasileña. El presente artículo tiene la finalidad de analizar la creación de uno de sus proyectos, el Centro Educacional Carneiro Ribeiro, un centro educativo, bajo la óptica de la democracia presente en el pensamiento deweyano y anisiano. Con este fin, hace un breve pasaje por la pedagogía de Dewey, adentrándose en su concepción de democracia y como ella influye su visión pedagógica y la compara con los objetivos pretendidos por Anísio Teixeira con la creación del centro en barrio obrero de Salvador a finales de la década de 40.

PALABRAS CLAVE: Anísio Teixeira. Democracia. Educación democrática. Centro Educacional Carneiro Ribeiro.

ABSTRACT: Anisio Teixeira was part of the group of Brazilian educators that had dedicated their public lives to designing education in Brazil. Inspired by John Dewey's educational philosophy, Anisio Teixeira based his pedagogical thought on it, expanding and adapting it to the needs of Brazilian society of his time. This article aims to analyze the creation of one of

1 Universidade de São Paulo (USP), São Paulo - SP - Brasil. Graduando em Física. ORCID: http://orcid.org/0000-0002-0279-9042. E-mail: lucassilvat@gmail.com

Rev. Sem Aspas, Araraquara, v. 9, n. 2, p. 196-206, jul./dez. $2020 . \quad$ e-ISSN: 2358-4238 
his many projects, the Carneiro Ribeiro Educational Center, an educational center, under the Anisian and Deweyan democratic concept. To this end, this article explores the surface of Dewey's educational thought, with focus on his notion of democracy, and how it influenced Anisio's philosophy, comparing it to Anisio's goals in the creation of the Educational Center in a working class neighborhood, in Salvador/BA, at the end of the 1940s.

KEYWORDS: Anísio Teixeira. Democracy. Democratic education. Centro Educacional Carneiro Ribeiro.

\section{Introdução}

No $120^{\circ}$ ano após o nascimento de Anísio Teixeira, sua obra e suas ideias se fazem ainda muitíssimo atuais. Anísio, que dedicou sua vida a entender e praticar a educação no Brasil, via na escola pública instrumento de semeação e perpetuação da democracia na vida social em seu sentido mais amplo (MAGOGA; MURARO, 2020).

Numa sociedade como a nossa, tradicionalmente marcada de profundo espírito de classe e de privilégio, somente a escola pública será verdadeiramente democrática e somente ela poderá ter um programa de formação comum, sem preconceitos contra certas formas de trabalho essenciais à democracia (FÁVERO, 2000, p. 179 apud TEIXEIRA, 1958).

É necessário, portanto, educar a todos, sem distinção de classe social. Educação é um direito, e não um privilégio. Esse pensamento perpassa o desejo de construção de uma educação de qualidade. Vai além. Serve de projeto de construção de uma sociedade verdadeiramente democrática. A escola para Anísio se ressignifica como um projeto da sociedade desejada, em um ideal que conecta os educandos à realidade e os insere na vida social, cívica e comunitária.

A atualidade do pensamento anisiano para a escola pública se concretiza ao olharmos não somente para a situação dessa escola nos dias de hoje, mas também para a própria sociedade brasileira, que é desigual nas oportunidades aos seus cidadãos de diferentes classes, raças, gênero, e outras formas de discriminação social (BRASIL, 2020). A relação entre a educação e a sociedade democrática é intrínseca (TEIXEIRA, 1984). Investir em uma educação universal, laica e gratuita é investir no progresso.

Com isso em mente, Anísio dá início a um de seus muitos projetos ousados: o Centro Educacional Carneiro Ribeiro, objeto dessa pesquisa e que serve para exemplificar sua ideia de democratização da educação. Também conhecido por Escola Parque, o Centro ofereceu aos alunos educação gratuita e integral, em bairro periférico de Salvador, colocando-os em contato com, além das disciplinas tradicionais, as artes, música, dança, tecelagem, tapeçaria, 
atividades desportivas, entre outras tantas áreas do saber (CORDEIRO, 2001, p. 243). A Escola Parque inseria ainda o estudante em uma vida comunitária e proporcionava-o higiene e alimentação (NUNES, 2000, p. 12), viabilizando, portanto, a permanência dos educandos mais carentes. Dessa forma, essa Escola, que projetou Anísio internacionalmente, é a concretização do seu ideal democrático.

No momento em que nos aprofundamos na concepção de democracia e de sociedade democrática de Anísio, precisamos, para entendê-la por completo, adentrar no pensamento filosófico de John Dewey, pois ele faz das ideias deste suas bases filosóficas.

\section{Dewey e a democracia}

John Dewey (1859-1952) foi um proeminente filósofo e pedagogo estadunidense. Edificada sobre as bases do pragmatismo, sua extensa obra rejeita os dualismos exacerbados e excludentes entre conceitos metafísicos e epistêmicos, reconstruindo-os como elementos constitutivos de uma só continuidade (HILDEBRAND, 2018). Dessa forma, para Dewey era impossível dissociar a teoria da prática, o pensamento da ação, a mente do corpo, a matéria do método educativo. Juntos, formam um todo que como todo devem ser vistos e manipulados. Negar a dicotomia desses elementos é expandi-los juntos em conceito e conjuntura. Ressignificam-se. A mente (teoria) não observa passivamente o mundo (prática), observa-o, sim, mas experimentando-o, adaptando-se e inovando-se (HILDEBRAND, 2018). E o mundo não é isento de mente, uma vez que se transforma em suas experiências conjuntas. Há de se ter uma ponte, não somente em ligação, mas que ela própria os contenha - teoria e prática - ao passo que quando se transforma um, se transforma o outro, quando se sabe um, se sabe o outro, ou seja, fazem parte do todo. Para Dewey, o método não se distingue da matéria, pois aquele é o modo pelo qual se processa a experiência enquanto este é o objeto da própria experiência, não se distinguindo nem método ou matéria de experiência, e, consequentemente, método de matéria (WESTBROOK, 2010, p. 55).

Essa unidade influi significativamente no processo educativo. $\mathrm{O}$ aprendizado não se descola do indivíduo-educando. Só se efetiva, pois faz parte do seu modo de viver (WESTBROOK, 2010, p. 56) e por isso se torna de suma importância levar em consideração o seu interesse. Ora, mais facilmente o educando absorverá para si conceitos e práticas que o interesse. Dewey, dessa forma, segue a linha dos escolanovistas de sua época ao colocar também a criança no centro da prática pedagógica, mas se descola dos mesmos quando os coloca em oposição extrema aos tradicionalistas. 


\begin{abstract}
"Direção e controle" são palavras mágicas de uma escola; "liberdade e iniciativa", as da outra. Proclamam-se a lei e a ordem com fundamento de uma; a espontaneidade é o que se busca na outra. Voltam-se os carinhos aqui para o que é antigo, para a conservação do que o passado conquistou com esforço e labor; novidade, mudança e progresso vencem acolá todas as afeições. Inércia e rotina por um lado, caos e anarquia do outro, são as mútuas acusações condenatórias. A escola que faz da criança o centro de tudo é acusada de desprezar a autoridade sagrada do dever; por sua vez, ela ataca na sua opositora a supressão da individualidade pelo despotismo tirânico.

Tais oposições raramente são levadas até as suas últimas conclusões lógicas. Ao bom senso repugna o caráter extremo desses pontos de vista. Ficam eles para os teoristas, enquanto, praticamente, se adota um ecletismo confuso e pouco consistente (DEWEY, 2010, p. 72).
\end{abstract}

Sua filosofia pedagógica não deve ser entendida, no entanto, como um balanço entre "disciplina" e "interesse", "controle" e "liberdade", mas sim, e novamente, como unidade do todo entre esses extremos. O indivíduo não se faz isolado da sociedade, que também não se constitui sem indivíduos. Portanto, no processo educativo há de se levar em consideração ambas as partes, sem ponderá-las, mas unindo-as, de forma que os interesses individuais sejam estimulados e guiados pelos objetivos da sociedade para este indivíduo.

Aqui, o conceito de democracia e de educação para democracia vem para explicar essa relação. A democracia como valor inerente à sociedade e a educação para democracia como forma de perpetuação desse valor. Uma sociedade democrática imprescinde de uma educação para a democracia, pois senão está fadada a ser frágil em suas estruturas e instituições. Portanto, não basta ao indivíduo estar inserido na democracia, mas praticá-la, aceitá-la, do contrário sua própria relação com a democracia seria impositiva e, daí, incongruente. Essa ideia faz Dewey acreditar que o educando em seu processo de vivência chegaria à mesma conclusão, se em contato através da educação, e por isso o valor democrático deveria ser absorvido por si só, sem imposição. Deve ser um valor forte o suficiente para se sustentar (WESTBROOK, 2010, p. 30).

Como conceber uma escola que prepare o indivíduo para a democracia? Como vimos, Dewey discorre sobre a impossibilidade de imposição da democracia, ou, aliás, de qualquer conteúdo sobre a criança/adolescente. Se o fizesse, além da clara contradição com os métodos democráticos, estaria se contradizendo também em sua crítica aos tradicionalistas. Por outro lado, em um ambiente de pura liberdade, sem o mínimo controle, se desconsideraria a experiência coletiva histórica da humanidade. A sociedade-filha, fruto dessa educação, seria irreal (WESTBROOK, 2010, p. 42). Para resolver esse problema, volta-se ao educador, concebendo-o em sua pedagogia como a via condutora que liga o social ao indivíduo. 
Ao conceito de democracia não se vincula somente a ideia de governos constituídos sob regimes políticos democráticos, mas também a de que as relações internas nessa sociedade sejam justas, livres e de iguais oportunidades a todos que a constituem.

Para terem numerosos valores comuns, todos os membros da sociedade devem dispor de oportunidades iguais para aquele mútuo dar e receber. Deveria existir maior variedade de empreendimentos e experiências de que todos participassem. Não sendo assim, as influências que a alguns educam para senhores, educariam a outros para escravos. E a experiência de cada uma das partes perde em significação quando não existe o livre entrelaçamento das várias atividades da vida (DEWEY, 2010, p. 89).

Ainda, discorre que o isolamento entre os grupos sociais plurais e distintos intrasociedades e intersociedades é prejudicial ao crescimento dos mesmos, uma vez que se limitam a proteger suas conquistas a dividir experiências e, portanto, progredir.

Toda época de expansão na história da humanidade coincidiu com a atuação de fatores que tenderam a eliminar o afastamento entre povos e classes que dantes viviam isolados. Até os alegados benefícios das guerras quando de todo reais resultam do fato de que os conflitos entre as nações aumentam, pelo menos, as relações entre elas e, assim, incidentemente, habilita-as a aprenderem umas com as outras e a alargar, por essa forma, seus respectivos horizontes (DEWEY, 2010, p. 92).

Sobre esses dois pilares ergue seu conceito de democracia e o estende para a sociedade e, consequentemente, para a escola. Sua própria concepção de democracia era de espírito comunitário (HILDEBRAND, 2018).

\section{Anísio e a influência deweyana}

Anísio Spínola Teixeira (1900 - 1971) foi um político, pedagogo e filósofo brasileiro. Tal como seus contemporâneos educadores, assumiu a tarefa de pensar e praticar a educação brasileira já no fim da Primeira República Brasileira, herdando o espírito reformador do fim do século XIX e começo do século XX, se contrapondo, no entanto, na direção e na forma propostas pelos reformistas da educação. Anísio acreditava que a carência na formação dos brasileiros, principalmente dos menos afortunados, se devia pela omissão do Estado (NUNES, 2010), e não um sintoma do determinismo do darwinismo social.

Ao assumir o cargo de Inspetor Geral do Ensino em Salvador, Anísio, que teve formação nos colégios jesuítas em Caetité e na capital baiana, também formado pela Faculdade de Direito da Universidade do Rio de Janeiro, vai aos Estados Unidos a fim de ampliar seus conhecimentos pedagógicos, capacitando-se assim para o cargo que lhe 
concederam sem prévia experiência. Anísio se põe em contato com a obra de Dewey, que lhe dá instrumentação filosófica para entender, após contextualizadas, as mazelas sociais que afligiam a educação baiana e brasileira.

As ideias deweyanas reverberaram em Anísio, que não fez delas somente suas bases, mas também as elaborou, as praticou em contato com a administração pública do ensino em diversas ocasiões de sua vida profissional, as modificou e adaptou. Dewey foi um filósofo que enxergou a educação no mundo real, mas também ideal, uma vez que prevê a instituição da transformação. Anísio transformou o mundo real em que viveu. Para Nunes (2010, p. 45), Dewey voltava-se para o passado. Anísio, no entanto, para o futuro.

A Primeira República, regime político de quando nasceu, não era democrática. Tampouco o foi o Estado Novo ou todos os outros regimes subsequentes até a sua morte, que, mesmo alguns prevendo o voto popular, não eram verdadeiramente democráticos. Concordaria, se vivo fosse, que ainda não estamos vivendo nessa sociedade de ideal democracia, porque, apesar do voto universal, ainda as oportunidades são seletas para os grupos privilegiados. Anísio abraçou a ideia de sociedade democrática de Dewey, absorvendo-a em sua visão e prática pedagógica.

Para Anísio (TEIXEIRA, 1984), a democracia é “o regime mais difícil das educações, a educação pela qual o homem, todos os homens e todas as mulheres aprendem a ser livres, bons e capazes". A democracia não se distingue de educação, posição semelhante à de Dewey quando entende que um regime político democrático imprescinde de educação pois se faz com cidadãos igualmente democráticos.

Nascemos diferentes e desiguais, ao contrário do que pensavam os fundadores da própria democracia. Nascemos biologicamente desiguais. Se a democracia pode constituir-se para nós um ideal, um programa para o desenvolvimento indefinido da própria sociedade humana, é porque resolve o problema dessa dilacerante desigualdade. Oferecendo a todos oportunidades iguais para defrontar o mundo e a sociedade e a luta pela vida, a democracia aplaina as desigualdades nativas e cria o saudável ambiente de emulação em que ricos e pobres se sentem irmanados nas mesmas possibilidades de destino e de êxito. Esta, a justiça social por excelência da democracia. A educação é, portanto, não somente a base da democracia, mas a própria justiça social (DEWEY, 2010, p. 92).

Portanto, para Anísio, os indivíduos nascem e crescem diferentes. A democracia age como balanço, proporcionando a todas iguais condições de se desenvolverem em seus interesses e nos interesses da sociedade.

Como desenvolver, então, a democracia no Brasil em um contexto de predominância de oligarquias, governos autoritários, onde a distância entre as classes sociais é abismal e, 
consequentemente, se repete este mesmo cenário para a formação educativa dos cidadãos? Primeiro, seria necessário que a própria escola fosse democrática, em consonância com os valores deweyanos. Mas, tão importante quanto, a escola deveria ser acessível a toda população. A escola, para Anísio, deveria ser pública. É com esse pensamento que edifica sua vida profissional na educação.

\section{O Centro Educacional Carneiro Ribeiro}

Anísio foi filósofo e administrador público, estudante e professor, teórico e praticante. Ele solidificou em sua personalidade a concepção deweyana da unidade do dualismo. Viveu e praticou a democracia em suas ações. Sabia também que, para efetivamente tornar a sociedade brasileira democrática, era preciso estender a educação a todos, e que essa educação fosse democrática, não somente preparando o educando para o mundo, mas para o mundo democrático, que não foi verdadeiramente vivido até hoje no Brasil. É a partir desse ideal que concebeu este de seus muitos projetos, que serve aqui mais para ilustrar sua prática do que para atuar de forma taxativa.

Durante sua passagem como Secretário da Educação e Saúde do Estado da Bahia, no governo de Otávio Mangabeira, na inauguração do Centro Educacional discursa:

O começo que hoje inauguramos é modestíssimo: representa apenas um terço do que virá a ser o Centro completo. Custará, não apenas os sete mil contos que custaram estes três grupos escolares, mas alguns quinze mil mais. Além disto, será um centro apenas para 4.000 das 40.000 crianças que teremos, no mínimo, de abrigar nas escolas públicas desta nossa cidade. Deveremos possuir, e já não só este, como mais 9 centros iguais a este. Tudo isso pode parecer absurdo, entretanto, muito mais absurdo será marcharmos para o caos, para a desagregação e para o desaparecimento. E de nada menos estamos ameaçados. Os que estão, como cassandras, a anunciar e esperar a catástrofe e a subversão, irão fazer as escolas que deixamos de fazer para a vitória do seu regime. Se o nosso, o democrático, deve sobreviver, deveremos aparelhá-lo com o sistema educativo forte e eficaz que lhe pode dar essa sobrevivência. A inauguração que, hoje, aqui se faz, alimenta essa esperança e essa ambição. Bem sei que a ambição é desmedida, mas que medida tem a sobrevivência democrática? (TEIXEIRA, 1959).

O Centro Educacional Carneiro Ribeiro (CECR) seria um pontapé inicial para que outras escolas o seguissem, projeto que quando finalizado atenderia, portanto, à demanda real dos estudantes soteropolitanos.

Ainda em seu discurso de inauguração, Anísio defende a atuação plural no corpo docente do centro, de modo a fomentar a "cultura intelectual, social, artística e vocacional" 
dos alunos. O Centro Educacional foi verdadeiramente um projeto democrático, na medida que é público, serve a comunidade local, proporciona a vida comunitária e representou um projeto ambicioso de educação. A educação foi desenhada para ser inclusiva e por isso se instala no bairro operário da Liberdade, oferece aos estudantes alimentação gratuita, é integral e insere o educando em um ambiente de formação não somente para as disciplinas tradicionais, mas também para a construção do seu ideal cívico e comunitário. Vejamos ainda parte do discurso de abertura do Centro Educacional em que Anísio fala:

É contra essa tendência à simplificação destrutiva que se levanta este Centro Popular de Educação. Desejamos dar, de novo, à escola primária, o seu dia letivo completo. Desejamos dar-lhe os seus cinco anos de curso. E desejamos dar-lhe seu programa completo de leitura, aritmética e escrita, e mais ciências físicas e sociais, e mais artes industriais, desenho, música, dança e educação física. Além disso, desejamos que a escola eduque, forme hábitos, forme atitudes, cultive aspirações, prepare, realmente, a criança para a sua civilização - esta civilização tão difícil por ser uma civilização técnica e industrial e ainda mais difícil e complexa por estar em mutação permanente. E, além disso, desejamos que a escola dê saúde e alimento à criança, visto não ser possível educá-la no grau de desnutrição e abandono em que vive (TEIXEIRA, 1959).

O discurso se atenta à necessidade educativa das disciplinas tradicionais ("leitura, aritmética e escrita, e mais ciências físicas e sociais") mas considera também a inclusão curricular das "artes industriais", "desenho", "música”, “dança” e "educação física”. A escola prepara o aluno para a vida comunitária através da replicação da comunidade em seu currículo, não a que vivem os educandos - que por si só já havia privando-os dessas oportunidades - mas sim para uma sociedade ideal, democrática, idealizada por Dewey e Anísio. Vejamos ainda dois depoimentos dados por ex-alunos do Centro Educacional Carneiro Ribeiro:

Ex-aluno I: Anísio Teixeira é uma pessoa que fez com que o filho de uma servente da escola, um filho de um motorista chegasse à situação de médico sem precisar passar por cursos de complementação educacional.

Ex-aluna II: Sou a caçula de oito filhos, e se minha mãe não tivesse encontrado na vida o Centro eu não estaria, com certeza, na formação de educadora que estou hoje, por conta de que eu não ia ter condição de custear estudo de qualidade. Porque eu recebi estudo de qualidade (EDUCAÇÃO, 2007).

O CECR, portanto, deu oportunidade àqueles que, sem acesso ao mesmo, talvez tivessem sido preteridos pela sociedade. 
A escola contava com uma cantina que preparava a alimentação de todos os estudantes. Apesar de alheia ao processo pedagógico, a segurança alimentar dos educandos é igualmente importante, uma vez que sua garantia é necessária para o aproveitamento completo das demais atividades escolares (EDUCAÇÃO, 2007). O educando tinha ainda fomentado o seu desenvolvimento em algum ofício - destacando-se a importância dada ao seu interesse.

As técnicas em que se ocupam os alunos são as seguintes: cartonagem, encadernação, ou simples recuperação de livros, artefatos de couro, de metal, de madeira, modelagem, cerâmica, cestaria, alfaiataria, corte e costura, bordados diversos, confecção de bonecas e bichos, tapeçaria e tecelagem (EDUCAÇÃO, 2007).

A importância do Setor do Trabalho na Escola projetada por Anísio vai além da instrução profissional dada aos estudantes. Os alunos também desenvolvem habilidades motoras, independência e cooperação em grupo. Aprendem a dividir as atividades. A finalidade é ver florescer no alunato o amor ao trabalho; o aprender a trabalhar (EDUCAÇÃO, 2007).

Eram oferecidas ainda atividades físicas orientadas ou livres, no Setor Recreativo; aulas de música, dança e teatro no Setor Artístico; livros para leitura recreativa, estudo ou pesquisa, na Biblioteca (EDUCAÇÃO, 2007).

O espírito comunitário se fazia presente também no Setor Socializante, responsável por "espelhar" as relações sociais, internalizando-as à vida social escolar dos alunos, que podiam assumir responsabilidades e tarefas nas instituições edificadas para esse propósito: o Banco, o Jornal, a Rádio Escola, o Grêmio e a Loja. É, pois, responsável por fomentar a "integração na comunidade escolar", a "autonomia", "iniciativa", "responsabilidade", “cooperação", "honestidade”, “o respeito a si e aos outros” (EDUCAÇÃO, 2007).

Por fim, a comunidade escolar recebia ainda assistência material - para o fardamento, livros e materiais didáticos, e médico-odontológica. Anísio ainda previu em seu projeto moradia estudantil para acomodar $5 \%$ dos estudantes, considerados sem lar. Essa área infelizmente não se concretizou (EDUCAÇÃO, 2007).

\section{Considerações finais}

Anísio teve em Dewey uma fonte de inspiração e de conhecimento para atender às necessidades da Educação, principalmente pública, no Brasil. A ideia deweyana de democracia foi absorvida no pensamento de Anísio e praticada em suas ações como 
administrador público da Educação em seus diversos projetos, exemplificado pelo Centro Educacional Carneiro Ribeiro, concretização do ideal democrático anisiano. Os dois pilares da democracia de Dewey, o de amplas oportunidades a todos e o da diminuição dos espaços entre os grupos intersociedades e intrasociedades, se fazem presentes no projeto da escola, uma vez que é pública e instalada em bairro operário - portanto preconiza a absorção de setores populares da comunidade local, é integral e estimula a formação cívica dos seus alunos. A escola-parque deu oportunidade para que a população mais carente do bairro da Liberdade pudesse ter contato com uma educação libertadora, preparatória para uma sociedade verdadeiramente democrática.

\section{REFERÊNCIAS}

BRASIL. Instituto Brasileiro de Geografia e Estatística - IBGE. Trabalho, renda e moradia: desigualdades entre brancos e pretos ou pardos persistem no país. Agência IBGE Notícias, 2020. Disponível em: https://agenciadenoticias.ibge.gov.br/agencia-noticias/2012-agencia-denoticias/noticias/29433-trabalho-renda-e-moradia-desigualdades-entre-brancos-e-pretos-oupardos-persistem-no-pais. Acesso em: 31 dez. 2020.

DEWEY, J. Democracia e educação. In: BRASIL. Ministério da Educação. John Dewey. Coleção Educadores MEC. 2010.

EBOLI, T. Uma experiência de educação integral. Brasília, DF: INEP, 1969.

EDUCAÇÃO não é Privilégio. [S. I.: s. n.]. 2007. 1 vídeo (44 min). Direção de Mônica Simões. TV Escola.

FÁVERO, M. L. A. Educação não é privilégio. Rev. Bras. Educ., Rio de Janeiro, n. 14, p. 176-180, ago. 2000.

HILDEBRAND, D. John Dewey. The Stanford Encyclopedia of Philosophy. Stanford University: Metaphysics Research Lab, 2018. Disponível em:

https://plato.stanford.edu/archives/win2018/entries/dewey/. Acesso em: 31 dez. 2020.

MAGOGA, P. M.; MURARO, D. N. A escola pública e a sociedade democrática: a contribuição de Anísio Teixeira. Educ. Soc., Campinas, v. 41, e236819. set. 2020. ISSN 1678-4626. DOI: https://doi.org/10.1590/es.236819

NUNES, C. Anísio Teixeira entre nós: a defesa da educação como direito de todos. Educ. Soc., Campinas, v. 21, n. 73, p. 9-40, 2000.

NUNES, C. Anísio Teixeira. In: BRASIL. Ministério da Educação. Anísio Teixeira. Brasília, DF: Coleção Educadores MEC, 2010. 
TEIXEIRA, A. Escola pública não é invenção do socialismo nem do comunismo. Entrevista. Rio de Janeiro: O Globo, 1958. Disponível em:

http://www.bvanisioteixeira.ufba.br/artigos/ninvencao.html. Acesso em: $31 \mathrm{dez} .2020$.

TEIXEIRA, A. Centro Educacional Carneiro Ribeiro. Revista Brasileira de Estudos

Pedagógicos, Rio de Janeiro, v. 31, n. 73, p. 78-84, jan./mar. 1959. Disponível em

http://www.bvanisioteixeira.ufba.br/Visita Guiada/p5b21.htm. Acesso em: 31 dez. 2020.

TEIXEIRA, A. Educação e cultura na Constituição do Estado da Bahia. Revista Brasileira de Estudos Pedagógicos, Rio de Janeiro, v. 65, n. 151, p. 685-696, set./dez. 1984. Disponível em: http://www.bvanisioteixeira.ufba.br/artigos/educacao5.html. Acesso em: $31 \mathrm{dez} .2020$.

WESTBROOK, R. B. John Dewey. In: BRASIL. Ministério da Educação. Anísio Teixeira. Brasília, DF: Coleção Educadores MEC, 2010.

\section{Como referenciar este artigo}

TEIXEIRA, L. S. A experiência democrática de Anísio Teixeira: o projeto do Centro Educacional Carneiro Ribeiro. Rev. Sem Aspas, Araraquara, v. 9, n. 2, p. 196-206, jul./dez. 2020. e-ISSN: 2358-4238. DOI: https://doi.org/10.29373/sas.v9i2.14653

Submetido em: $20 / 01 / 2021$

Aceito em: 26/02/2021

Publicado em: 01/03/2021 